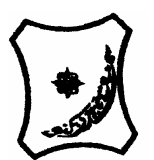

Bayero Journal of Pure and Applied Sciences, 9(2): 225 - 229

Received: June 2016

Accepted: November, 2016

ISSN $2006-6996$

\title{
OCCURRENCE AND ANTIBIOGRAM OF Staphylococcus aureus IN DAIRY PRODUCTS CONSUMED IN PARTS OF KADUNA STATE, NIGERIA
}

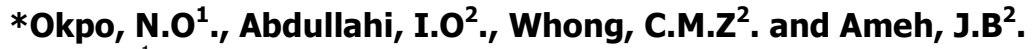 \\ ${ }^{1}$ Federal College of Agricultural Produce Technology, Kano \\ ${ }^{2}$ Department of Microbiology, Ahmadu Bello University, Zaria \\ *Correspondence author: elendungozi@yahoo.com; 08063910330
}

\begin{abstract}
A total of 160 dairy products comprising of 80 each of fresh milk and 'Nono' (Fermented and defatted) were collected. The samples were cultured and identified by routine bacteriological methods. Prevalence of S.aureus (8.75\%) in the products was; for fresh milk 3.75\% and 'Nono' $5 \%$. The susceptibility profile of the isolates to nine antimicrobial agents revealed a high susceptibility to Gentamicin (100\%), Ciprofloxaxin (92.86\%) and Chloramphenicol (92.86\%). The isolates had high resistance to Tetracycline (85.71\%), Cefoxitin (64.29\%), Amoxicillin/Clavulanic acid (64.29\%) and Erythromycin (64.29\%). A total of 9(64.29\%) isolates were resistant to multiple antibiotics. Multiple antibiotics resistance index (MARI) ranged from $7.14 \%(0.7)$ to $21.43 \%(0.3)$. The presence of S.aureus and resistance to commonly used antibiotics by the isolates posses a health risk for consumers of these milk products.
\end{abstract}

Key words: Dairy Products, Staphylococcus aureus, susceptibility profile, fresh milk, 'Nono'.

\section{INTRODUCTION}

Staphylococcal food borne intoxication is one of the most common forms of bacterial food-borne disease in many countries (Balaban and Rasooly, 2000). Milk is a good substrate for $S$. aureus growth and among the foods implicated in staphylococcal food poisoning (SFP), milk and dairy products play an important role, since enterotoxigenic strains of $S$. aureus have been frequently isolated in them (Normanno et al., 2007; Jorgensen et al., 2005).

Raw milk and Fermented milk of various types are produced and consumed as supplement to normal meals in homes and even for sale (Maduka et al., 2013). Many farm families consume raw milk simply because it is a traditional practice and less expensive to buying pasteurized retailed milk (Hegarty et al., 2002). Raw milk, other traditional dairy products such as 'Nono' (locally fermented milk), are often commonly hawked and consumed on many Northern Nigeria streets (Umoh et al., 1990). Staphylococcus aureus had been reported in fermented milk products (Fura and Manshanu) Umoh et al., 1990 and in 'Fura da Nono'; a cereal based food prepared from sorghum or millet (Umoh, 1989). These products due to their processing and distribution practices often are exposed to conditions which may permit growth of contaminating organisms and possible toxin producers (Ezeonu and Ezurike, 2007).

Presently it is difficult to ascertain the extent to which these indigenous dairy products contribute to food poisoning outbreaks. Consequently also of limited report are the antibiotic sensitivity patterns of bacterial pathogens associated with these dairy products. This study therefore investigates the prevalence and antibiogram of S.aureus in fresh milk and Nono (a fermented dairy product) commonly consumed in parts of Kaduna State, Nigeria.
MATERIALS AND METHODS

Study area

The study area included four (4) local government areas (Giwa, Kaduna North, Soba and Chikun) local government areas in Kaduna state.

\section{Sample collection}

A total of 160 samples; comprising of 80 samples each of Fresh milk and 'Nono' (20 from each local government area), were collected over a one year period. Fresh milk samples were collected from farm Steads or Fulani settlements while 'Nono' samples were obtained from motor parks and markets. The samples were collected in sterile containers and placed in ice-packed coolers then taken to the Department of microbiology laboratory, Ahmadu Bello University Zaria, for analysis.

\section{Enumeration and Isolation of Staphylococcus aureus}

This was conducted according to the procedure described by Imanifooladi et al. (2010). Each fresh milk and milk product sample was diluted in the ratio $1 / 100$ in normal saline. From each solution produced, $1 \mathrm{ml}$ was transferred to $9 \mathrm{mls}$ cook meat media culture with $9 \% \mathrm{NaCl}$ and incubated at $37^{\circ} \mathrm{C}$ for 48 hours. In the second phase, $0.1 \mathrm{ml}$ from each previously cultured medium was then transferred to Baird-Parker agar (BPA) and incubated for 24 hours. Black colonies with transparent zone on Baird-Parker agar were considered as presumptive Staphylococcus species. They were picked and stored on nutrient agar slants for further confirmation tests. 


\section{Biochemical Characterization of isolates}

Presumptive Staphylococcus species that were gram positive cocci in clusters were subjected to some biochemical tests as described by Cheesbrough (2009). Which were; coagulase, catalase, fermentation of glucose and Mannitol. These organisms were further confirmed using Microgen ${ }^{\mathrm{TM}}$ STAPH- identification system (Microgen Bioproducts, United Kingdom). Single colonies of the presumptive isolates were tested with 12 standardized biochemical substrates following the manufacturer's instructions. The test organisms were identified by interpreting the permutations of metabolized substrates using the microgen identification system software (MID-60).

\section{Antibiotic Sensitivity}

Antibiotic susceptibility tests for isolates of Staphylococcus aureus were performed according to the Kirby- Bauer method as described by Bauer et al., 1966, and the evaluation methods of the Clinical and Laboratory standards Institutes (CLSI) (CLSI, 2014). Isolates grown on nutrient agar overnight were suspended in $2 \mathrm{ml}$ sterile normal saline $(0.9 \%$ sodium chloride solution). A turbidity equivalent was prepared by comparing with a 0.5 MacFarland standards. Bacterial suspensions of $0.1 \mathrm{ml}$ were spread on plates of sterile Mueller-Hinton agar with the help of a sterile cotton swab to form a smooth bacterial lawn. Commercially prepared standard susceptibility test discs impregnated with known agent and strength were then dispensed on the agar surface. Characterizations of strains as susceptible, intermediate or resistant were based on the size of inhibition zone around the disc compared with the interpretation standards provided by the manufacturers.

Multiple antibiotic resistance (MAR) for this study is defined as resistance of isolate to three or more antibiotics (Lambert, 2002 and Osundiya et al., 2013). Multiple antibiotic resistance index (MARI) was calculated according to Furtula et al. (2013) as the ratio of number of antibiotics to which an organism is resistant, to the total number of antibiotics to which an organism is exposed to.

\section{RESULTS}

Out of the total of 160 samples examined, S.aureus strains (14) were isolated from the two products. Fresh milk had a higher frequency of occurrence 8 $(5 \%)$ of S.aureus than 'Nono' which had a frequency of $6(3.75 \%)$. The percentage occurrence of S.aureus in the different sampling locations is shown in Figure 1. Soba had the highest occurrence of S.aureus 5 (35.71\%) while Giwa had the least occurrence of 2 (14.29\%). Kaduna north and Chikun local government areas had $4(28.57 \%)$ and $3(21.43 \%)$ occurrences respectively.

The antibiotics susceptibility pattern of the isolates is shown in Table 2 . The isolates showed $100 \%$ (14) susceptibility to Gentamicin and the least activity was observed with Tetracycline $14.29 \%$ (2). A total of 9 (64.29\%) were resistant to multiple antibiotics (Figure 2). Multiple antibiotics resistance index (MARI) ranged from 1 (0.4 and 0.7$)$ to $3(0.3)$

Table 1: Frequency of contamination of dairy products with $S$. aureus.

\begin{tabular}{lccl}
\hline Sample Type & Sample no & No. Positive (\%) & No. Negative (\%) \\
\hline Fresh milk & 80 & $6(3.75)$ & $74(46.25)$ \\
Nono & 80 & $8(5)$ & $72(45)$ \\
Total & 160 & $14(8.75)$ & $146(91.25)$ \\
\hline
\end{tabular}

Key: $n=160$.

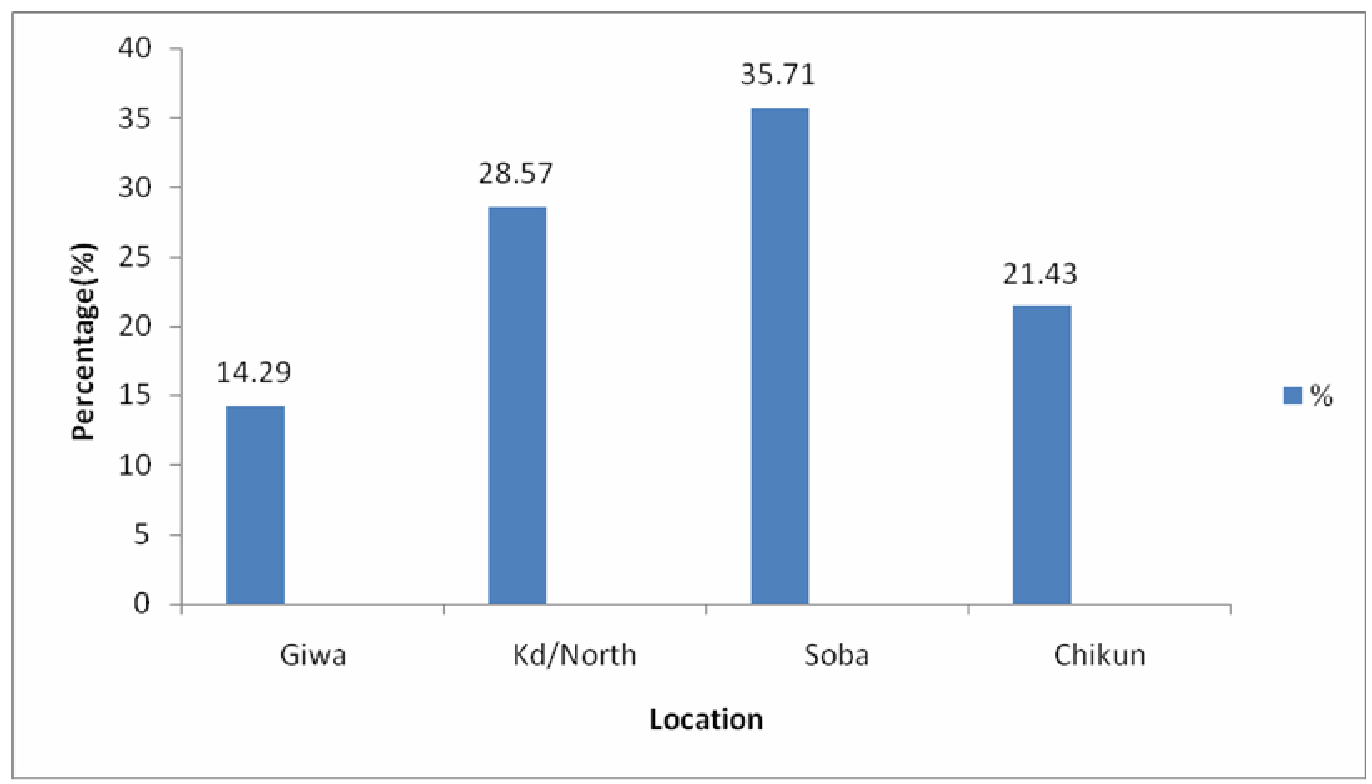

Figure 1: Occurrence of $S$. aureus in the selected local government areas. 
Table 2: Antibiotics susceptibility Profile of $S$. aureus isolates from Fresh milk and Nono isolates.

\begin{tabular}{lll} 
& \multicolumn{1}{c}{ Susceptibility (\%) } & No. Susceptible \\
Antibiotics (Conc.jg) & & \\
\hline Amoxicillin/Clavulanic acid (30) & $9(64.29)$ & $5(35.71)$ \\
Cefoxitin (30) & $9(64.29)$ & $5(35.71)$ \\
Chloramphenicol (30) & $1(7.14)$ & $13(92.86)$ \\
Ciprofloxacin (5) & $1(7.14)$ & $13(92.86)$ \\
Erythromycin (15) & $9(64.29)$ & $5(35.71)$ \\
Gentamicin (10) & 0 & $14(100)$ \\
Tetracycline (30) & $12(85.71)$ & $2(14.29)$ \\
Trimethoprim/Sulfamethoxazole (25) & $5(35.71)$ & $9(64.29)$ \\
Vancomycin (30) & $7(50.0)$ & $7(50.0)$ \\
\hline
\end{tabular}

Key: $\mathrm{n}=14$

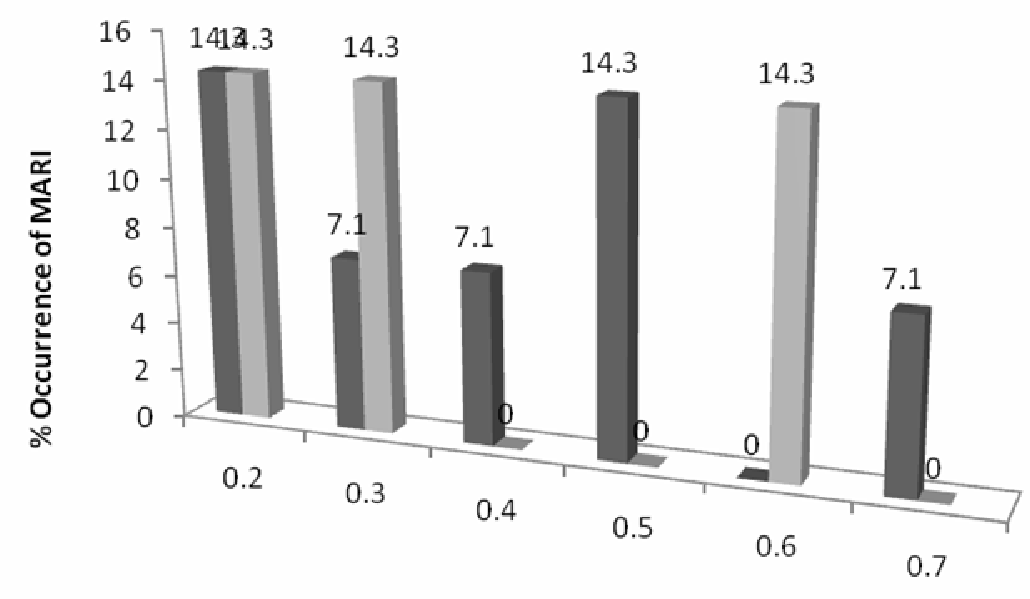

MAR Index of $S$. aureus isolates from fresh milk and Nono samples

Figure 2: Percentage occurrence of Multiple Antibiotics Resistance Indices (MARI) among S.aureus isolates.

\section{Discussion}

The isolation of Staphylococcus aureus in milk products from this research is of public health significance, since it is said to be a commonly recovered pathogen in outbreaks of food poisoning due to milk and dairy products (Junaidu et al., 2011). The occurrence of S.aureus $(8.75 \%)$ in the four locations might refer to improper public health measurement, sanitary and poor cleaning of people concerned with milk marketing. In addition, the primitive system of transportation and marketing practiced in these locations may also be predisposing factors. Staphylococcus aureus may originate from mastitic animals or human sources (Akram et al., 2013; Oliver et al., 2005).

Isolates demonstrated high susceptibility to Gentamicin, Ciprofloxacin and Chloramphenicol. This may have implications on the effectiveness of the local and probably antibiotics resistance control programs. The high performance of some of these antibiotics (Gentamicin, Ciprofloxacin and Chloramphenicol) could also be due to their molecular sizes a factor which enhances their solubility in diluents thus promoting their penetration power through cell wall into the cytoplasm of the target microorganism. This finding is in line with Mailard (2002) and Poole (2002) who respectively opined that the high efficacy of antibiotics may be traced to their molecular sizes. The present study revealed a high resistance to tetracycline (85.71\%), a commonly used antibiotic by the $S$. aureus isolates. This trend of resistance is therefore a matter of concern for humans, for livestock disease management and production in general owning to the existing emergence of bacterial strains resistant to other major antibiotics. The use of antibiotics in food animals have been reported to enhance the spread of bacteria resistant to antibiotics via the food to humans and cause human infection (Phillips et al., 2004).

Multidrug resistance for this study is defined as resistance of isolate to three or more antibiotics (Lambert, 2002 and Osundiya et al., 2013). MAR index was calculated as the ratio of number of antibiotics to which an organism is resistant to total number of antibiotics to which an organism is exposed (Furtula et al., 2013). 
MAR index values greater than 0.2 indicates high risk source of contamination where antibiotics are often used (Furtula et al., 2013). The residues of antibiotics have also been reported in tissues of food animals and their products (Kabir et al. 2004; Adesokan et al. 2013). The high percentage occurrence of multiple antibiotics resistance (MAR) index (64.29\%) among the $S$. aureus isolates might have arisen due to common practices such as self medication and over the counter usage of antibiotics. In addition to this is continued administration of antibiotics repeatedly against infections that appear non-responsive to the normal dose given earlier (Ezenduka et al. 2011).

\section{Conclusion}

The occurrence of $S$. aureus $(3.75 \%)$ in fresh milk and Nono $(5 \%)$ consumed in these locations posses a

\section{REFERENCES}

Adesokan, H.K., Agada, C.A., Adetunji, V.O. and Akanbi, I.M. (2013). 'Oxytetracycline and penicillin-G residues in cattle slaughtered in south-western Nigeria: Implications for livestock disease management and public health', Journal of the South African Veterinary Association. 84(1), 945:1-5.

Akram N, Chaudhary, A. H, Ahmed, S, Ghuma, M. A, Nawaz, G and Hussain, S.(2013). Isolation of Bacteria from Mastitis Affected Bovine Milk and their Antibiogram. European Journal of Veterinary Medicine, 2, (1):38-46.

Balaban, N. and Rasooly, A. (2000). Staphylococcal Enterotoxins. International Journal of Food Microbiology, 61:110 - 114 .

Bauer, A. W., Kirby, W. M. M., Sherris, J. C. and Turck, M. (1966). Antibiotic susceptibility Testing By a Standardized single disk method. American Journal of Clinical Pathology, 36:493-496.

Cheesbrough, M. (2009). District Laboratory Practice in Tropical Countries, Part 2.Cambridge lowprice edition. United Kingdom.

Clinical and Laboratory standards Institutes (CLSI). (2014). Performance Standards for antimicrobial susceptibility testing; $24^{\text {th }}$ Informational Supplement.CLSI document M100- S24.Wayne, PA: Clinical and Laboratory Standards Institute.Volume $\mathbf{3 4}$ (1): M100-S24.

Ezenduka, E.V., Oboegbulem, S.I., Nwanta, J.A. and Onunkwo, J.I.(2011). 'Prevalence of Antimicrobial Residues In Raw Table Eggs From Farms And Retail Outlets in Enugu State, Nigeria', Tropical Animal Health and Production. 43(3):557-559.

Ezeonu, I.M. and Ezurike, O.A. (2007). Isolation and Characterization of enterotoxigenic Staphylococcus aureus from Yoghurt samples. In: Igbinosa I.B. (Ed.). Annals of Natural Sciences,volume 7(1):1-12.

Furtula, V.,Jackson, C.R, Farell, E.G, Barrett, J.B., Hiott, L.M. and Chambers, P.A. (2013). Antimicrobial Resistance in Enterococcus spp. serious public health threat for consumers of these local dairy products particularly as the transfer of pathogens via such food chain is very well documented. Antibiogram of bacterial isolates revealed high performance of some of the antibiotics used such as gentamicin, ciprofloxacin and chloramphenicol while a high resistance was observed for tetracycline $(85.71 \%)$, a commonly used antibiotics thereby posing a public health concern.

\section{Recommendation}

There is therefore need to institute effective control measures to protect public health from these food borne pathogens. This would include mandatory milk pasteurization by traders and improved hygienic handling of the commodity during milking.

Isolated from Environmental Samples in an Area of Intensive Poultry Production. International Journal of Environmental Research and Public Health, 10,1020-1036. Galan, J. E. (1996). Molecular Genetic Bases of Salmonella Entry into Host Cells. Molecular Microbiology. 20: 263-271.

Hegarty, H,O'Sullivan, M.B, Buckley, J. and FoleyNolan.(2002).Continued Raw Milk Consumption of Farms:why? Community Discuss. Public Health, 5:151-156.

Imanifooladi, A.A, Tavakoli, H.R and Naderi, A. (2010). Detection of enterotoxigenic Staphylococcus aureus isolates in domestic dairy products. Iranian Journal of Microbiology.2:(3) 135-140.

Jorgensen, H.J, Mark, T.,Hogasen, H.R.and Rovik, L.M (2005). Enterotoxigenic Staphylococcus aureus in bulk milk in Norway.Journal of Applied Microbiology, 99, 158-167.

Junaidu, A.U., Salihu, M.D., Tambuwal, F.M., Magaji, A.A. and Jaafaru, S. (2011). Prevalence of Mastitis in lactating cows in some selected commercial Dairy farms in Sokoto Metropolis. Advances in Applied Science Research, 2(2):290-294.

Kabir, J., Umoh, V.J., Audu-Okoh, E., Umoh, J.U and Kwaga, J.K.P. (2004). 'Veterinary drug use in poultry farms and determination of antimicrobial drug residue in commercial eggs and slaughtered chicken in Kaduna state, Nigeria', Food Control,15, 99-105..

Lambert, P.A. (2002). Mechanisms of antibiotic resistance in Pseudomonas aeruginosa. Journal of the Royal society of medicine. 95 (41):22-26.

Maduka, H.C.C, Ugwu, C.E, Maduka, A.A, Hashidu, N.H and Gimba B.S. (2013). Microbial Screening and Lipid peroxidation status of fermented (Yoghurt) milk samples sold in Maiduguri Metropolis and commonly consumed in university of Maiduguri Bornu State, Nigeria. British Journal of Dairy sciences, 3(2):14-21. 
Mailard, J. Y. ( 2002). Bacterial target sites for biocide action. Journal of Applied Microbiology. 82.53-60.

Normanno, G., Salandra, G.L., Dambrosio, A., Quaglia, N.C., Corrente, M., Parisi, A., Santagada, G., Firinu, A., Crisetti, E., Celano, G.V.(2007). Occurrence, characterization and antimicrobial resistance of enterotoxigenic Staphylococcus aureus isolated from meat and dairy products. International Journal of Food Microbiology, 115, 290-296.

Oliver, S.P, Javarao, B.M, Almeida, R.A. (2005). Food Borne Pathogens In Milk And The Dairy Farm Environment: Food Safety And Public Health Implication. Food borne Pathogens and Diseases, 2(2):115-129.

Osundiya, O.O, Oladele, R.O and Oduyebo, O.O. (2013). Multiple antibiotic resistance (MAR) indices of Pseudomonas and Klebsiella species isolates in Lagos University Teaching Hospital. African Journal of Clinical and Experimental Microbiology.Volume 14(3) 164-168.
Phillips, I., Casewell, M., Cox, T., De Groot, B., Friis, C. and Jones, R. (2004). 'Does the use of antibiotics in food animals pose a risk to human health? A critical review of published data', Journal of Antimicrobial Chemotherapy. 53, 28-52. http://dx.doi. org/10.1093/jac/dkg483

Poole, K. (2002). Mechanism Of Bacterial Biocide And Antibiotic Resistanse. Journal of Applied Microbiology. 92: 55-64.

Umoh, V. J., Adesiyun, A. A. and Gomwalk, N. E. (1990). Enterotoxigenicity of Staphylococci isolated from raw milk obtained from settled and Nomadic herds around Zaria, Nigeria. Journal of Veterinary Medicine. 43(1):43 47.

Umoh,V.J. (1989). Contamination of Fura-Da-Nono by Staphylococci and Growth of an enterotoxigenic Staphylococcus aureus in Fura, A cereal food. Zariya Veterinarian. Volume 4(2). 